\title{
ANALISIS FAKTOR-FAKTOR YANG MEMPENGARUHI PRODUKSI PADI SAWAH DI KELURAHAN KOYA, KECAMATAN TONDANO SELATAN
}

\author{
Alvio G. Onibala \\ Mex L. Sondakh \\ Rine Kaunang \\ Juliana Mandei
}

\begin{abstract}
ABSRACT
This study aims to determine the influence of the use of production factors on rice farming production. This research was conducted in Urban Village of Koya, Sub-district of South Tondano, Minahasa District by using primary data and secondary data. Sampling in this research was done by using Simple Random Sampling method with 60 farmers as respondents. The variables measured in this research are production, land area, amount of labor, amount of phonska fertilizer, amount of urea fertilizer, number of seeds and amount of pesticide. The data analysis used is Cobb Douglas model regression analysis to see the influence of each factor of production on the produced production. Simultaneously variable of land area, seed, urea fertilizer, phonska fertilizer, pesticide and labor have an effect on rice field production in Koya. Individual variables of land area, urea seed and fertilizer have a significant effect on rice production.
\end{abstract}

Keywords: analysis, factors, rice field, Koya Urban Village, South Tondano Sub-district, Minahasa District

\begin{abstract}
ABSTRAK
Penelitian ini bertujuan untuk mengetahui pengaruh faktor-faktor produksi terhadap hasil produksi pada usahatani padi sawah. Penelitian ini dilaksanakan di Kelurahan Koya Kecamatan Tondano Selatan dengan menggunakan data primer dan sekunder. Pengambilan sampel dalam penelitian ini dilakukan dengan metode simple random sampling dengan 60 petani sebagai responden. Variabel yang diukur dalam penelitian ini yaitu produksi, luas lahan, jumlah tenaga kerja, jumlah pupuk phonska, jumlah pupuk urea, jumlah benih dan jumlah pestisida. Analisis data yang digunakan yakni analisis regresi model Cobb Douglas untuk melihat pengaruh masingmasing faktor produksi terhadap hasil produksi yang dihasilkan. Secara serentak variabel luas lahan, benih, pupuk urea, pupuk phonska, pestisida dan tenaga kerja berpengaruh terhadap produksi padi sawah di Kelurahan Koya. Secara individu variabel luas lahan, benih dan pupuk urea berpengaruh signifikan terhadap produksi padi.
\end{abstract}

Kata kunci: analisis, faktor-faktor, padi sawah, Kelurahan Koya, Kecamatan Tondano Selatan, Kabupaten Minahasa 


\section{PENDAHULUAN}

\section{Latar Belakang}

Di Indonesia, sektor pertanian berperan penting dalam pembangunan dan perekonomian nasional. Sebagian besar penduduk Indonesia bermata pencaharian sebagai petani. Peranan sektor pertanian sangatlah penting yaitu sebagai penyedia bahan pangan, penyedia bahan baku bagi industri-industri, penyedia kesempatan berusaha, serta merupakan sumber pendapatan bagi para petani. Salah satu komoditas pertanian yang sangat dibutuhkan masyrakat adalah padi. Padi merupakan komoditi penghasil beras yang menjadi tanaman pangan utama bagi penduduk Indonesia. Beberapa alasan penting perlu ditingkatkan produksi padi secara keberlanjutan yaitu beras merupakan bahan pangan pokok bagi masyarakat Indonesia, merupakan komoditas penting umtuk menjaga ketahanan pangan, usaha tani padi sudah merupakan bagian hidup dari petani Indonesia sehingga menciptakan lapangan kerja yang besar dan kontribusi dari usaha tani padi terhadap pendapatan rumah tangga cukup besar (Hamdan, 2013). Indonesia merupakan salah satu negara konsumen beras terbesar di dunia. Semakin meningkatnya jumlah penduduk berarti kebutuhan pangan juga akan semakin meningkat (Srirande, 2012). Dengan bertambahnya jumlah penduduk dari tahun ke tahun maka, berbagai upaya dilakukan pemerintah untuk meningkatkan produktivitas pangan khususnya beras dalam hal memenuhi kebutuhan penduduk. Peningkatan produksi inilah yang menjadi target dan tujuan kegiatan pertanian (Pongoh, 2014)

Usahatani merupakan kegiatan mengusahakan faktor-faktor produksi berupa lahan, tenaga kerja, dan modal sehingga memberikan hasil yang maksimal. Penggunaan faktor produksi dan penerapan teknologi memegang peranan penting. Penggunaan faktor produksi dan penerapan teknologi yang kurang tepat akan mengakibatkan rendahnya produksi dan tingginya biaya usahatani. Dalam usahatani, produk yang dihasilkan akan baik apabila faktor produksi yang ada dimanfaatkan secara efisien
(Zulkifli, 2009). Salah satu kecamatan di Kabupaten Minahasa yang menjadi daerah penghasil padi adalah Kecamatan Tondano Selatan. Dari delapan Kelurahan yang ada di Kecamatan Tondano Selatan, hanya satu Kelurahan yang tidak memproduksi padi yaitu Kelurahan Maesa Unima. Berikut data luas panen, indeks panen, produktivitas dan jumlah produksi padi sawah di kecamatan tondano selatan disajikan dalam Tabel 1.

Tabel 1. Data Luas Panen, Indeks Panen, Produksi dan Produktivitas Padi Sawah di Kecamatan Tondano Selatan Tahun 2014

\begin{tabular}{|c|c|c|c|c|c|}
\hline No & Kelurahan & $\begin{array}{l}\text { Luas } \\
\text { Panen } \\
\text { (Ha) }\end{array}$ & $\begin{array}{l}\text { Indeks } \\
\text { Panen }\end{array}$ & $\begin{array}{l}\text { Produksi } \\
\text { (Ton) }\end{array}$ & $\begin{array}{l}\text { Produktivitas } \\
\text { (Ton/Ha) }\end{array}$ \\
\hline 1 & Tataaran II & 10 & 2 & 54 & 5,4 \\
\hline 2 & Tataaran I & 204 & 2 & 1101,8 & 5,4 \\
\hline 3 & Koya & 270 & 2 & 1512 & 5,6 \\
\hline 4 & $\begin{array}{l}\text { Maesa } \\
\text { Unima }\end{array}$ & - & - & - & - \\
\hline 5 & Tounsaru & 104 & 2 & 582,4 & 5,6 \\
\hline 6 & $\begin{array}{l}\text { Tataaran } \\
\text { Patar }\end{array}$ & 38 & 2 & 205,2 & 5,4 \\
\hline 7 & Paleloan & 1 & 1 & 5,4 & 5,4 \\
\hline 8 & Urongob & 1 & 1 & 5,4 & 5,4 \\
\hline
\end{tabular}

Sumber : BP3K, Kecamatan Tondano Selatan, 2014

Tabel 1 menunjukan bahwa kelurahan Koya merupakan penghasil padi terbesar di Kecamatan Tondano Selatan dengan luas lahan panen sebesar 270 ha dan produksi 1512 ton. Hal ini menunjukan bahwa di Kelurahan Koya padi sawah menjadi salah satu pilihan bagi petani untuk bercocok tanam demi meningkatkan pendapatan dan kesejahteraan keluarga petani. Untuk mendapatkan keuntungan dan produksi yang maksimal, maka petani harus mengetahui faktor-faktor apa yang mempengaruhi produksi agar supaya mendapat hasil yang maksimal. Karena itu perlu dilakukan penelitian tentang analisis faktor-faktor yang mempengaruhi produksi padi sawah.

\section{Perumusan Masalah}


Berdasarkan penjelasan di atas, maka yang menjadi rumusan masalah dalam penelitian ini adalah bagaimana pengaruh penggunaan faktor-faktor produksi pada usahatani padi sawah di Kelurahan Koya ?

\section{Tujuan Penelitian}

Penelitian ini bertujuan untuk mengetahui pengaruh penggunaan faktor-faktor produksi pada usahatani padi sawah di Kelurahan Koya.

\section{Manfaat Penelitian}

Manfaat penelitian ini adalah memberikan informasi kepada petani padi sawah di daerah penelitian agar dapat mengolah usahatani dengan menggunakan faktor produksi secara tepat demi meningkatkan produksi padi dan pendapatan keluarga, juga sebagai bahan informasi bagi peneliti selanjutnya.

\section{METODOLOGI PENELITIAN}

\section{Waktu dan Tempat Penelitian}

Penelitian ini akan dilaksanakan selama 3 bulan dari bulan april sampai bulan juni 2015 mulai dari persiapan pengambilan data sampai pada penyusunan laporan hasil penelitian. Penelitian ini berlokasi di Kelurahan Koya Kecamatan Tondano Selatan.

\section{Metode Pengumpulan Data}

Penelitian ini menggunakan data primer dan sekunder. Data primer adalah data yang diperoleh secara langsung dari petani untuk mendapatkan data yang diperlukan, melalui interview (wawancara) dan kuesioner dan data sekunder adalah data-data yang didapat dari sumber lain yang berfungsi sebagai data pendukung, yaitu dari buku-buku ataupun hasilhasil laporan penelitian yang pernah dilakukan dan data dari dinas pertanian maupun instansiinstansi terkait di kabupaten minahasa.

\section{Metode Pengambilan Sampel}

Pengambilan sampel dalam penelitian ini dilakukan dengan metode.Simple Random Sampling. Jumlah populasi petani padi sawah di daerah penelitian sebanyak 210 petani. Pengambilan sampel sebanyak $30 \%$ dari jumlah populasi yakni 60 petani padi sawah.

\section{Konsep Pengukuan Variabel}

Variabel-variabel yang diukur dalam penelitian ini adalah:

1. Produksi (kg/musim tanam) : Padi yang dihasilkan dalam satu kali musim tanam.

2. Luas lahan (Ha) : Lahan yang ditanami padi.

3. Jumlah Tenaga Kerja (HOK) : Jumlah tenaga kerja yang digunakan dalam satu kali musim tanam (setara hari kerja pria).

4. Jumlah Pupuk Urea (kg) : Jumlah pupuk yang digunakan dalam satu kali musim tanam.

5. Jumlah Pupuk Phonska (kg) : Jumlah pupuk yang digunakan dalam satu kali musim tanam.

6. Jumlah benih (kg) : Jumlah benih yang digunakan dalam satu kali musim tanam.

7. Jumlah Pestisida (ltr) : Jumlah pestisida yang digunakan dalam satu kali musim tanam.

\section{Analisis Data}

Data dianalisis menggunakan analisis regresi model Cobb Douglas untuk melihat pengaruh masing-masing faktor produksi terhadap produksi yang dihasilkan. Bentuk ekonometrik: $\mathbf{Y}$ $=\beta_{0} \cdot X_{1}^{\beta 1} \cdot X_{2}^{\beta 2} \cdot X_{3}^{\beta 3} \cdot X_{4}^{\beta 4} \cdot X_{5}^{\beta 5} \cdot X_{6}^{\beta 6} \cdot E$. Transformasi ke bentuk logaritma: $\mathbf{L n} Y=\ln \boldsymbol{\beta}_{\mathbf{0}}+$ $\beta_{1} \ln X_{1}+\beta_{2} \ln X_{2}+\beta_{3} \ln X_{3}+\beta_{4} \ln X_{4}+\beta_{5} \ln X_{5}+$ $\beta_{6} \ln X_{6}+\ln \varepsilon$

Dimana :

$\begin{array}{rlrl}\mathrm{Y} & = & \text { Produksi }(\mathrm{kg}) \\ \mathrm{X}_{1} & = & \text { Luas Lahan }(\mathrm{Ha}) \\ \mathrm{X}_{2} & = & \text { Tenaga Kerja }(\mathrm{HOK}) \\ \mathrm{X}_{3} & = & \text { Pupuk Urea }(\mathrm{Kg}) \\ \mathrm{X}_{4} & = & \text { Pupuk Phonska }(\mathrm{Kg}) \\ \mathrm{X}_{5} & = & \text { Benih }(\mathrm{Kg}) \\ \mathrm{X}_{6} & = & \text { Pestisida (L) } \\ \beta_{1,}, \beta_{2}, \beta_{3,}, \beta_{4}, \beta_{5}, \beta_{6,}= & \text { Koefisien regresi luas lahan, } \\ & & \text { TK, pupuk, benih, pestisida } \\ \varepsilon & \text { Residual / faktor-faktor lain } \\ & & \text { yang berpengaruh yang } \\ & \text { tidak dimasukkan dalam } \\ & \text { model. }\end{array}$

\section{HASIL DAN PEMBAHASAN}

\section{Gambaran Umum Wilayah Penelitian}

\section{Letak dan Luas Wilayah Penelitian}

Kelurahan Koya termasuk dalam wilayah Kecamatan Tondano Selatan dan terbentuk sejak tahun 1890. Adapun batasan- 
batasan wilayah Kelurahan Koya sebagai berikut : Sebelah utara berbatasan dengan Kelurahan Wewelan. Sebelah timur berbatasan dengan Kelurahan Tataaran, Tuutu. Sebelah selatan berbatasan dengan Kelurahan Rerewokan. Sebelah barat berbatasan dengan Kelurahan Watulambot, Rerewokan. Luas Kelurahan Koya 451 Ha yang terdiri dari 7 lingkungan. Luas area persawahan $135 \mathrm{Ha}$, pekuburan $2 \mathrm{Ha}$, fasilitas umum sekitar $6 \mathrm{Ha}$, sisanya pemukiman dan perkebunan.

\section{Penduduk dan Agama}

Jumlah penduduk Kelurahan Koya adalah sebanyak 2.533 jiwa yang terdiri dari 1.215 laki-laki dan 1.318 perempuan dengan jumlah kepala keluarga 742 KK. Penduduk Kelurahan Koya sebagian besar beragama Kristen Protestan, selebihnya Katolik dan Islam.

\section{Sarana Pendidikan}

Kelurahan Koya menyediakan sarana prasarana yaitu dua gedung Sekolah Dasar (SD), satu gedung Taman Kanak-kanak (TK) dan satu gedung Pendidikan Anak Usia Dini (PAUD)

\section{Keadaan Umum Petani Responden}

\section{Umur Responden}

Umur petani memiliki hubungan dengan kemampuan petani dalam bekerja. Umur petani akan mempengaruhi produktivitasnya dalam mengelola usahatani. Dari segi fisik, semakin tua seseorang ketika melewati batasan umur tertentu akan berkurang kemampuannya dalam bekerja. Umur petani responden dapat dilihat pada Tabel 2.

Tabel 2. Jumlah Petani Responden menurut Kelompok Umur di Kelurahan Koya

\begin{tabular}{lll}
\hline $\begin{array}{l}\text { Umura } \\
\text { (Tahun) }\end{array}$ & $\begin{array}{l}\text { Jumlah } \\
(\text { Orang) }\end{array}$ & $\begin{array}{l}\text { Presentase } \\
(\%)\end{array}$ \\
\hline $31-36$ & 4 & 6.67 \\
$37-42$ & 8 & 13.33 \\
$43-48$ & 18 & 30.00 \\
$49-54$ & 7 & 11.67 \\
$55-60$ & 13 & 21.67 \\
$61-66$ & 8 & 13.33 \\
$>67$ & 2 & 3.33
\end{tabular}

\begin{tabular}{lll}
\hline Jumlah & 60 & 100.00 \\
\hline
\end{tabular}

Sumber : Diolah dari data primer 2015

Tabel 2 menunjukan bahwa jumlah responden terbanyak pada kelompok umur 4348 sebanyak 18 responden atau 30.00 persen dari total responden, diikuti oleh kelompok umur 55-60 sebanyak 13 responden atau 21.67 persen, untuk kelompok umur 37-42 dan 61-66 sama-sama berjumlah 8 responden atau 13.33 persen, kelompok umur 49-54 sebanyak 7 responden atau 11.67 persen, kelompok umur 31-36 sebanyak 4 responden atau 6.67 persen dan kelompok umur $>67$ sebanyak 2 responden atau 3.33 persen.

\section{Tingkat Pendidikan}

Pendidikan merupakan salah satu faktor yang penting dalam usaha peningkatkan kualitas sumber daya manusia, serta sangat menentukan dalam mengolah usahataninya, karena pendidikan akan mempengaruhi cara berpikir petani. Berdasarkan hasil penelitian, tingkat pendidikan petani responden bervariasi mulai dari Sekolah Dasar (SD) sampai Sekolah Menengah Atas (SMA) dapat dilihat pada Tabel 3.

Tabel 3. Jumlah Petani Responden menurut Tingkat Pendidikan di Kelurahan Koya

\begin{tabular}{lllc}
\hline No & Tingkat Pendidikan & Jumlah & Presentase \\
\hline 1 & SD & 16 & $26.67 \%$ \\
2 & SMP & 23 & $38.33 \%$ \\
3 & SMA & 21 & $35.00 \%$ \\
\hline & Jumlah & 60 & $100.00 \%$ \\
\hline
\end{tabular}

Sumber : Diolah dari data primer 2015

Tabel 3 dapat dilihat bahwa tingkat pendidikan dengan jumlah responden terbanyak yaitu SMP dengan jumlah 23 responden atau 38.33 persen, diikuti tingkat pendidikan SMA dengan jumlah 21 responden atau 35.00 persen dan tingkat pendidikan SD berjumlah 16 responden atau 26.67 persen.

\section{Jumlah Tanggungan Keluarga}

Jumlah tanggungan terdiri dari petani itu sendiri, istri, anak dan anggota keluarga lain yang menjadi tanggungan petani. Keluarga petani dapat menjadi sumber tenaga kerja dalam usahatani padi. Jumlah petani responden berdasarkan tanggungan keluarga dapat dilihat dalam Tabel 4. 
Tabel 4 menunjukan bahwa jumlah tanggungan keluarga terbanyak adalah 3-4 yang berjumlah 32 responden atau 53.33 persen, diikuti jumlah tanggungan keluarga 1-2 sebanyak 24 responden atau 40.00 persen dan jumlah tanggungan keluarga 5-6 berjumlah 4 responden atau 6.67 persen.

Tabel 4. Jumlah Petani Responden menurut Jumlah Tanggungan Keluarga di Kelurahan Koya

\begin{tabular}{lll}
\hline Jumlah Tanggungan Keluarga & Jumlah & Presentase \\
\hline $1-2$ & 24 & $40.00 \%$ \\
$3-4$ & 32 & $53.33 \%$ \\
$5-6$ & 4 & $6.67 \%$ \\
\hline Jumlah & 60 & $100.00 \%$ \\
\hline Sumber : Diolah dari data primer 2015
\end{tabular}

\section{Luas Lahan}

Luas lahan merupakan salah satu faktor yang mempengaruhi produksi. Semakin luas lahan maka hasil produksi semakin bertambah. Begitupun sebaliknya, jika luas lahan semakin sempit maka hasil produksi semakin sedikit. Luas lahan responden bervariasi antara 0.5 hektar sampai 4 hektar. Jumlah petani responden menurut luas lahan dapat dilihat pada Tabel 5.

Table 5. Luas Lahan Usahatani Padi di Kelurahan

\begin{tabular}{ccc} 
Koya & & \\
\hline Luas Lahan & Jumlah & Presentase \\
\hline $0-0.99$ & 5 & $8.33 \%$ \\
$1-1.99$ & 30 & $50.00 \%$ \\
$2-2.99$ & 20 & $33.33 \%$ \\
$3-3.99$ & 4 & $6.67 \%$ \\
$>4$ & 1 & $1.67 \%$ \\
\hline Jumlah & 60 & $100.00 \%$ \\
\hline \multicolumn{2}{l}{ Sumber : Diolah data primer tahun 2015}
\end{tabular}

Tabel 5 dapat dilihat bahwa luas lahan yang paling banyak diolah petani adalah 1-1.99 hektar dengan jumlah responden 30 atau 50.00 persen, diikuti luas lahan 2-2.99 hektar sebanyak 20 responden atau 33.33 persen, untuk luas lahan 0-0.99 sebanyak 5 responden atau 8.33 persen, untuk luas lahan 3-3.99 hektar sebanyak 4 responden atau 6.67 persen dan untuk luas lahan $>4$ adalah sebanyak 1 responden atau 1.67 persen.

\section{Analisis Faktor Yang Mempengaruhi Produksi Padi}

Summary Output dapat dilihat pada Tabel 6.

Tabel 6. Summary Output
Multiple R

0.999989383

R Square

Adjusted R Square

0.999978766

Standard Error

0.981458281

Observations

0.043650131

Hasil pengujian seperti yang terlihat

pada Tabel Summary Output menunjukan bahwa koefisien determinasi (R2) dalam model regresi adalah sebesar 0,999 atau 99,9\%. Nilai koefisien determinasi $99,9 \%$ artinya variable yang meliputi luas lahan, benih, urea, phonska, pestisida dan tenaga kerja dapat menjelaskan produksi padi di kelurahan koya sebesar 99,9\%.

\begin{tabular}{ccccc}
\multicolumn{6}{l}{ Tabel 7. Anova } & & & \\
\hline$d f$ & $S S$ & $M S$ & $F$ & $\begin{array}{c}\text { Significance } \\
F\end{array}$ \\
\hline 6 & 4845.262082 & 807.5436804 & 423833.1498 & $3.5037 \mathrm{E}-122$ \\
54 & 0.102888032 & 0.001905334 & & \\
60 & 4845.36497 & & & \\
\hline
\end{tabular}

Tabel 7 menunjukan bahwa pengaruh signifikan variable luas lahan, benih, urea, phonska, pestisida dan tenaga kerja secara serentak terhadap produksi padi dapat dilihat pada Tabel Anova. Dari hasil pengujian nilai signifikan sebesar 0,000 sehingga menunjukan bahwa variable-variabel tersebut secara serentak berpengaruh signifikan terhadap produksi padi. Berdasarkan analisis regresi, maka diperoleh fungsi produksi padi sawah sebagai berikut: $\mathrm{LnY}=\mathbf{0 , 9 3 3}-\mathbf{0 , 2 8 9}+\mathbf{0 , 2 2 1}+\mathbf{0 , 0 1 8}+\mathbf{0 , 1 9 6}-$ $\mathbf{0 , 0 8 5}$. Hasil analisis menunjukan bahwa faktor produksi yang mempengaruhi produksi padi sawah adalah luas lahan, benih dan pupuk urea.

a. Pengaruh luas lahan terhadap produksi. Luas lahan mempengaruhi produksi dengan taraf signifikan sebesar $1 \%$ dan nilai koefisien untuk variabel luas lahan adalah 0,9331. Berarti setiap penambahan $1 \%$ luas lahan maka produksi meningkat sebesar 0,9331 .

b. Pengaruh benih terhadap produksi. Benih mempengaruhi produksi dengan taraf signifikan sebesar $1 \%$ dan nilai koefisien untuk variable benih adalah 0,1962. Berarti setiap penambahan $1 \%$ benih maka akan meningkatkan produksi sebesar 0,1962.

c. Pengaruh urea terhadap produksi. Urea mempengaruhi produksi dengan taraf signifikan sebesar $1 \%$ dan nilai koefisien untuk variable urea adalah 0,2214. Berarti setiap penambahan urea $1 \%$ maka akan meningkatkan produksi sebesar 0,2214 . 
d. Pengaruh phonska terhadap produksi. Nilai koefisien untuk variabel phonska adalah 0,0184 dimana phonska tidak berpengaruh terhadap produksi. Pengaruh pestisida terhadap produksi. Nilai koefisien untuk variable pestisida adalah 0,0851 dimana pestisida tidak berpengaruh terhadap produksi. Setiap penambahan pestisida akan mengurangi produksi.

e. Pengaruh tenaga kerja terhadap produksi. Tenaga kerja tidak mempengaruhi produksi karena nilai koefisien untuk variable tenaga kerja adalah -0,2899. Penambahan tenaga kerja sudah tidak lagi efisien karena koefisien bernilai negatif.

\section{KESIMPULAN DAN SARAN}

\section{Kesimpulan}

Dari hasil penelitian yang telah dilakukan luas lahan, benih, urea, phonska, pestisida dan tenaga kerja terhadap produksi padi sawah di kelurahan koya, maka dapat disimpukan bahwa secara serentak variabel luas lahan, benih, urea, phonska, pestisida dan tenaga kerja berpengaruh terhadap produksi padi sawah dikelurahan koya. Secara individu variabel luas lahan, benih dan pupuk urea berpengaruh signifikan terhadap produksi padi.

\begin{abstract}
Saran
Saran kepada petani supaya memperhatikan penggunaan faktor produksi dengan baik sesuai dengan anjuran Badan Penyuluh Pertanian. Kepada pemerintah dan pihak-pihak terkait kiranya dapat memberikan penyuluhan dan pelatihan kepada petani agar bisa meningkatkan produksi.
\end{abstract}

\section{DAFTAR PUSTAKA}

Hamdan. 2013. Analisis Efisiensi Penggunaan Faktor Produksi pada Usahatani Padi Sawah di Bengkulu. Balai Pengkaji Teknologi Pertanian. Bengkulu.

Kasturi, A. 2012. Analisis Faktor-Faktor Yang Mempengaruhi Produksi Padi Di Kabupaten Wajo. UNHAS. Makassar.
Mubyarto. 1995. Pengantar Ekonomi Pertanian. LP3S. Jakarta.

Pongoh, D. 2014. Efisiensi Penggunaan Faktor Produksi Pada Usahatani Padi Sawah Di Kelurahan Tondangow Kecamatan Tomohon Selatan. UNSRAT. Manado.

Pusat Penyuluhan Pertanian Badan Penyuluhan dan Pengembangan SDM Pertanian. 2011. Budidaya Padi. BPPSDM Pertanian. Jakarta.

Rahardja dan Manurung. 2006. Teori Ekonomi Mikro Suatu Pengantar. Fakultas Ekonomi Universitas Indonesia. Jakarta.

Sarwoko. 2005. Dasar-dasar Ekonometrika. Penerbit Andi. Yogyakarta.

Srirande, 2012, "Pertumbuhan Provinsi Agraris". Kencana, Jakarta.

Soekartawi. 1995. Dasar Penyusunan Suatu Proyek. Pustaka Sinar Harapan. Jakarta.

Sugiarto, H. 2010. Ekonomi Mikro Sebuah Kajian Komprehensif. PT Gramedia Pustaka. Jakarta

Widarjono. 2007. Ekonometrika Teori dan Aplikasi Untuk Ekonomi dan Bisnis. Penerbit Erlangga. Jakarta

Zulkifli. 2009. Analisis Efisiensi Penggunaan Faktor Produksi pada Usahatani Jagung Studi Kasus Petani Jagung di Kel, Panreng Kec. Sidrap. 